\title{
Ever-smoking, quitting, and psychiatric disorders: evidence from the Durham, North Carolina, Epidemiologic Catchment Area
}

\author{
Lirio S Covey, Dana C Hughes, Alexander H Glassman, Dan G Blazer, Linda K George
}

\begin{abstract}
Objective-To examine the association between cigarette smoking and psychiatric disorders.

Design-The relationship between 11 psychiatric disorders and both eversmoking and quitting or reducing smoking was determined by odds ratio analysis. Statistical adjustment was employed to control for the influence of comorbidity among "smoking-related" psychiatric disorders as well as age, race, education, and urban $v s$ rural residence. Outcome measures-Ever-smoking-a history of smoking at least one cigarette a day for one month or more. Quit/cut down-made a cessation attempt and succeeded in smoking less than 10 cigarettes a day for at least 12 months.

Participants -2980 individuals from the Durham, North Carolina (USA) epidemiologic catchment area interviewed in 1981-83.

Results-A history of ever-smoking was associated with alcohol abuse/dependence and generalized anxiety disorder among men and women. Men with generalized anxiety disorder and women with recurrent-episode major depression showed a decreased likelihood of quitting or cutting down. A weak association was observed between ever-smoking and single-episode major depression in both genders. There was no excess of eversmokers among individuals with schizophrenia but the quit rate in this group was nil.
\end{abstract}

Conclusion - Significant associations between certain psychiatric disorders and cigarette smoking behaviour exist. These associations provide clues for developing smoking control interventions tailored to the presence of those disorders and contribute as well towards improved management of smoking-related psychiatric disorders.

(Tobacco Control 1994; 3: 222-227)

Waal-Manning et al reported several years ago that "negative affect", a broad concept referring to states such as depression, anxiety, and tension, was higher among smokers than nonsmokers. ${ }^{1}$ Since then, negative affect has also been implicated as a reason for failure at smoking cessation attempts ${ }^{2}$ and as the most common antecedent of a smoking relapse. ${ }^{3}$. The first report of an association between smoking and psychiatric status was published in 1986 by Hughes et al who showed that smoking prevalence was significantly higher among those with major depression, anxiety, and schizophrenia. ${ }^{4}$ Since that study, several others have reported an association between a history of ever smoking cigarettes and major depression, ${ }^{5-12}$ alcohol abuse/dependence ${ }^{7,9}$ anxiety disorders, ${ }^{9}$ and schizophrenia. ${ }^{13-15} \mathrm{~A}$ detrimental influence of major depression, ${ }^{6-8,10}$ but not of any other psychiatric disorder, on the ability to stop smoking has also been reported.

This study extends current knowledge regarding the relationship between cigarette smoking behaviour and psychiatric morbidity using epidemiological data collected in 1981-83 from Durham, North Carolina (USA). Using this data set, we examined the relationships between several psychiatric disorders and ever-smoking and quitting. Because of well-known gender differences in rates of our study variables (ie, ever-smoking and the quit rate are higher in men, ${ }^{16}$ major depression and anxiety disorders are more common in women, and alcohol abuse/dependence is more common in men $^{17}$ ), we performed genderspecific analyses. Additionally, recent data suggesting that the association of major depression with cigarette smoking may arise primarily from recurrent, rather than singleepisode major depression ${ }^{18}$ (J Angst, University of Zurich, personal communication, 1991), prompted us to disaggregate major depressive disorders accordingly.

Methods

SUBJECTS

Data were obtained from 2980 community respondents from Durham, North Carolina, who participated in Wave 1 (1981-82) and Wave 2 (1983) of the National Institute of Mental Health-Epidemiologic Catchment Area (NIMH-ECA) study. Durham was one of five sites that took part in an epidemiological 
study assessing the prevalence of psychiatric disorders in the US adult population, which is extensively described elsewhere. ${ }^{19}$ The Durham ECA programme used a stratified, multistage sampling design. In the first stage, US census districts (tracts, binary area, and enumeration districts) were selected. In the second stage, smaller segments within the districts were selected and all housing units in those segments were enumerated. In the third stage, households were selected within segments. In the fourth and final stage respondents were identified within households, using the Kish method ${ }^{20}$ to select a single respondent per household. In addition to the primary sample, an oversample of approximately 900 persons aged 60 and older was obtained. The response rate at the baseline interview was $79 \%$.

\section{VARIABLES}

Study information was collected by trained lay interviewers using a structured interview which had the Diagnostic Interview Schedule $(\mathrm{DIS})^{21}$ as its core and included items about smoking behaviour. For this study, we used ever-smoking and quit/cut down status as the dependent variables. Ever-smoking: all subjects were asked if they had ever smoked cigarettes daily for a month or more; positive respondents to this question were labelled "eversmokers". Quit/cut down. All ever-smokers were asked if they had ever tried to quit. If they responded positively, they were then asked how long ago they had not smoked more than one-half pack per day. It was not asked specifically, however, if such former smokers had stopped smoking completely. Accordingly, the category "quit/cut down" represents smokers who had attempted to quit and were smoking less than 10 cigarettes daily for the past year or longer. Data from our smoking clinic has shown that smokers who attempt to stop but only manage to reduce their intake invariably return to their pre-quit attempt smoking level. Although that tendency may not apply to every smoker who attempts to quit (eg, less addicted smokers who do not present for smoking cessation treatment), that observation from our clinic suggests that a fair proportion of those who fall into the quit/cut down category may be complete abstainers.

Demographic characteristics (ie, sex, age, race, education, place of residence) and 11 psychiatric disorders derived with computer algorithms based on DSM-III criteria ${ }^{22}$ were examined for associations with ever-smoking and quit/cut down. The psychiatric disorders were: major depression (separated into single and recurrent types), dysthymia, generalised anxiety disorder, simple phobia, social phobia, agoraphobia, panic disorder, obsessive-compulsive disorder, alcohol abuse/dependence, schizophrenia, and antisocial personality.

We used information obtained in Wave 1 for all variables with the exception of items needed to make a diagnosis of generalised anxiety. Since the generalised anxiety items were obtained only at the Wave 2 interview, we adjusted the prevalence rate to include only those cases which had been reported as beginning prior to the Wave 1 interview. Reports of generalised anxiety that began in the interval between the Wave 1 and Wave 2 interview were considered "non-cases".

\section{STATISTICAL PROCEDURES}

Weights were developed to adjust for nonresponse and probability of selection within households of varying sizes, to downweight the oversample to its proportion in the population, and to match the 1980 census characteristics of the five-county area sampled. In the tables, the numbers of cases shown represent unweighted data whereas the percentages represent weighted data. All statistical tests were based on weighted data.

Chi-square tests were performed for the analyses of demographic variables and $p$ values less than 0.05 (two-tailed) were considered statistically significant. The odds ratio (OR) was used to measure the association between each psychiatric disorder and ever-smoking or quit/cut down. All subjects were used in the analyses of ever-smoking; only ever-smokers were used in the analyses for quit/cut down.

Odds ratios with $95 \%$ confidence intervals (CI) that did not include one were considered statistically significant. In the analyses for ever-smoking, odds ratios greater than one signified the higher likelihood of ever-smoking among individuals with the disorder in question. In the analyses for quit/cut down, odds ratios less than one indicated a lower quit rate. For those associations which approached or reached statistical significance, we performed gender-specific multiple logistic regression to adjust for the effects of other demographic variables (ie, age, race, education, and urban $v s$ rural residence) as well as psychiatric comorbidity. In the regression models, a specific disorder of interest was the dependent variable. Because the data are cross-sectional, odds ratios derived from the logistic regression can only be interpreted as indications of correlational, not antecedent or causal, relationships.

\section{Results}

The sample included slightly more women $(55 \%)$ than men. The average age of the sample was 42.8 years (SD 17.5); $30 \%$ were between 18-29 years, $28 \%$ between $30-44$, $29 \%$ between $45-64$, and $14 \%$ over 65 years old. Sixty-six per cent had completed high school, $37 \%$ were black, and $54 \%$ were urban residents.

\section{DEMOGRAPHIC CHARACTERISTICS BY SMOKING} STATUS

Table 1 shows that ever-smoking was significantly more frequent among men than women, among those in the ages 30-64 than either older or younger age groups, among whites compared to blacks, and among those with less than 13 years of schooling, but was 
Table 1 Demographic characteristics in Durham ECA 1981-83 $(n=2980)$, by ever-smoker and quit/cut down status

\begin{tabular}{|c|c|c|c|c|}
\hline & \multicolumn{2}{|c|}{ Ever-smoker ${ }^{a}$} & \multicolumn{2}{|c|}{ Quit/cut down } \\
\hline & $n$ & $\%$ & $n$ & $\%$ \\
\hline Males & 786 & $67.6^{\star \star}$ & 296 & $33.0^{\star}$ \\
\hline Females & 700 & 42.5 & 218 & 28.5 \\
\hline \multicolumn{5}{|c|}{ Age (years): } \\
\hline $18-29$ & 267 & $48.3^{\star \star}$ & 43 & $15.2^{\star \star}$ \\
\hline $30-44$ & 377 & 55.9 & 108 & 30.1 \\
\hline $45-64$ & 493 & 57.5 & 172 & 37.3 \\
\hline $65-94$ & 349 & 39.0 & 171 & 52.9 \\
\hline \multicolumn{5}{|c|}{ Education (years): } \\
\hline$\leqslant 8$ & 335 & $53.4^{\star \star}$ & 130 & $30.8^{\star \star}$ \\
\hline $9-12$ & 709 & 53.7 & 196 & 23.7 \\
\hline$\geqslant 13$ & 440 & 48.3 & 187 & 43.6 \\
\hline \multicolumn{5}{|l|}{ Race: } \\
\hline White & 1003 & $52.1^{\star}$ & 397 & $36.8^{\star \star}$ \\
\hline Black & 480 & 45.7 & 116 & 20.2 \\
\hline \multicolumn{5}{|l|}{ Residence: } \\
\hline Rural & 762 & 48.8 & 232 & $25.2^{\star \star}$ \\
\hline Urban & 724 & 51.0 & 282 & 36.1 \\
\hline
\end{tabular}

${ }^{\star} \mathrm{p}<0.01,{ }^{\star \star} \mathrm{p}<0.001$

Percentages shown are based on all respondents in the category.

Percentages shown are based on all ever-smokers in the category.

not significantly different by rural vs urban residence. Table 1 also shows that male gender, older age, higher education, being white, and urban residence were all significantly associated with a higher quit/cut down rate.
PSYCHIATRIC DIAGNOSIS AND SMOKING STATUS The rates of psychiatric disorders in all respondents and by smoking status (neversmoking, ever-smoking, and quit/cut down) as well as odds ratios and $95 \%$ confidence intervals for the associations between each diagnosis and ever-smoking and quitting are shown in table 2 for men and table 3 for women. Among men, odds ratios greater than two were observed for alcohol abuse/ dependence, generalised anxiety, and single major depression, but the excess of eversmokers suggested by those odds ratios was statistically significant only for the first two diagnoses. For quitting, an odds ratio less than one, suggesting a decreased likelihood of stopping smoking, was statistically significant only for generalised anxiety disorder, and approached statistical significance $(95 \% \mathrm{CI}=$ 0.5-1.0) for alcohol abuse/dependence.

Among women, statistically significant odds ratios indicated an excess of ever-smokers among those with alcohol abuse/dependence and generalised anxiety (table 3 ). Interestingly, the odds ratio for women with alcohol disorders was almost two times greater than that observed for men (4.9 vs 2.8). The odds ratio for ever-smoking among women with single

Table 2 Lifetime prevalence and odds ratios showing the association of psychiatric disorders with cigarette smoking status among females in the Durham ECA study (1981-83)

\begin{tabular}{|c|c|c|c|c|c|c|c|}
\hline & \multirow[b]{2}{*}{$\begin{array}{c}\text { Total } \\
(n)\end{array}$} & \multicolumn{4}{|c|}{ Cigarette smoking status } & \multirow[b]{2}{*}{$\begin{array}{l}\text { Ever-smoking } \\
O^{+} R^{a}\left(95 \% C I^{b}\right.\end{array}$} & \multirow[b]{2}{*}{$\begin{array}{l}\text { Quit/cut down } n^{++} \\
O R^{a}(95 \% C I)^{b}\end{array}$} \\
\hline & & $\begin{array}{c}\text { Total } \\
(1162) \\
\%\end{array}$ & $\begin{array}{c}\text { Never } \\
(376) \\
\%\end{array}$ & $\begin{array}{c}\text { Ever } \\
(786) \\
\%\end{array}$ & $\begin{array}{c}\text { Quit } \\
(296) \\
\%\end{array}$ & & \\
\hline $\begin{array}{l}\text { Alcohol abuse/dependence } \\
\text { Generalised anxiety disorder } \\
\text { Major depression }\end{array}$ & $\begin{array}{r}197 \\
56\end{array}$ & $\begin{array}{r}15.9 \\
5.7\end{array}$ & $\begin{array}{l}8.0 \\
3.0\end{array}$ & $\begin{array}{r}19.9 \\
7.1\end{array}$ & $\begin{array}{r}15.4 \\
4.2\end{array}$ & $\begin{array}{l}2.8(2.0-4.2) \\
2.4(1.3-4.4)\end{array}$ & $\begin{array}{l}0.7(0.5-1.0) \\
0.5(0.5-0.9)\end{array}$ \\
\hline single & 10 & 0.7 & 0.4 & 0.9 & 1.1 & $2.5(0.5-13.3)$ & $1.4(0.3-5.9)$ \\
\hline recurrent & 14 & 1.2 & 1.1 & 1.2 & 1.4 & $1.1(0.4-3.2)$ & $1.3(0.4-43)$ \\
\hline Dysthymia & 11 & 1.0 & 0.7 & 1.2 & 0.9 & $1.7(0.5-6.0)$ & $0.7(0.2-2.9)$ \\
\hline Agoraphobia & 45 & 4.3 & 3.6 & 4.7 & 4.0 & $1.3(0.7-2.3)$ & $0.9(0.4-1.7)$ \\
\hline Social phobia & 26 & 3.0 & 3.4 & 2.9 & 2.2 & $0.8(0.4-1.6)$ & $0.8(0.3-2.0)$ \\
\hline Simple phobia & 159 & 13.8 & 12.6 & 14.5 & 12.7 & $1.2(0.8-1.2)$ & $0.8(0.5-1.2)$ \\
\hline Obsessive-compulsive disorder & 22 & 2.0 & 3.1 & 1.5 & 0.7 & $0.5(0.2-1.0)$ & $0.5(0.1-2.5)$ \\
\hline Panic disorder & 6 & 0.7 & 1.3 & 0.4 & 2.8 & $0.3(0.1-1.2)$ & $2.0(0.2-16.4)$ \\
\hline Antisocial personality disorder & 20 & 2.4 & 1.8 & 2.7 & 2.3 & $1.6(0.7-3.5)$ & $0.8(0.3-2.0)$ \\
\hline Schizophrenia & 8 & 1.0 & 1.1 & 1.0 & 0.0 & $0.9(0.3-2.8)$ & $0.1(0.006-1.8)$ \\
\hline
\end{tabular}

a Crude odds ratios.

b $95 \%$ confidence intervals that exclude one indicate statistical significance.

+ Analyses included all subjects.

++ Analyses included only ever-smokers.

Table 3 Lifetime prevalence and odds ratios showing the association of psychiatric disorders with cigarette smoking status among females in the Durham ECA study (1981-83)

\begin{tabular}{|c|c|c|c|c|c|c|c|}
\hline & \multirow[b]{2}{*}{$\underset{n}{\text { Total }}$} & \multicolumn{4}{|c|}{ Cigarette smoking status } & \multirow[b]{2}{*}{$\begin{array}{l}\text { Ever smoking } \\
\text { OR }^{a}(95 \% C)^{b}\end{array}$} & \multirow[b]{2}{*}{$\begin{array}{l}\text { Quit/cut down } n^{++} \\
\operatorname{OR}^{a}(95 \% C I)^{b}\end{array}$} \\
\hline . & & $\begin{array}{c}\text { Total } \\
(1818) \\
\%\end{array}$ & $\begin{array}{c}\text { Never } \\
(1118) \\
\%\end{array}$ & $\begin{array}{c}\text { Ever } \\
(700) \\
\%\end{array}$ & $\begin{array}{c}\text { Quit } \\
(218) \\
\%\end{array}$ & & \\
\hline Alcohol abuse/dependence & 28 & 1.8 & 0.7 & 3.4 & 1.9 & $4.9(2.1-11.5)$ & $0.5(0.2-1.5)$ \\
\hline Generalised anxiety disorder & 156 & 9.4 & 7.4 & 11.8 & 9.6 & $1.6(1.2-2.2)$ & $0.8(0.4-1.3)$ \\
\hline \multicolumn{8}{|l|}{ Major depression } \\
\hline recurrent & 47 & 2.8 & 2.4 & $\begin{array}{l}2.0 \\
3.0\end{array}$ & $\begin{array}{l}2.7 \\
0.4\end{array}$ & $\begin{array}{l}2.0(1.0-4.1) \\
1.1(0.6-2.1)\end{array}$ & $\begin{array}{l}0.9(0.3-2.6) \\
0.1(0.01-0.95)\end{array}$ \\
\hline Dysthymia & 61 & 3.3 & 3.2 & 3.5 & 4.1 & $1.1(0.6-1.9)$ & $1.3(0.5-3.1)$ \\
\hline Agoraphobia & 199 & 10.1 & 10.1 & 10.1 & 8.7 & $1.0(0.7-1.4)$ & $0.8(0.4-1.4)$ \\
\hline Social phobia & 72 & 5.0 & 4.8 & 5.1 & 4.1 & $1.1(0.7-1.7)$ & $0.7(0.3-1.7)$ \\
\hline Simple phobia & 392 & 21.3 & 20.8 & 22.0 & 21.8 & $1.1(0.8-1.4)$ & $1.0(0.7-1.5)$ \\
\hline Obsessive-compulsive disorder & 63 & 3.4 & 3.7 & 3.0 & 2.1 & $0.8(0.5-1.4)$ & $0.7(0.2-2.0)$ \\
\hline Panic disorder & 30 & 2.2 & 1.7 & 2.8 & 3.2 & $1.6(0.8-3.2)$ & $1.2(0.4-3.2)$ \\
\hline Schizophrenia & 15 & 1.3 & 1.2 & 1.5 & 0.0 & $1.2(0.5-2.7)$ & $0.1(0.007-2.1)$ \\
\hline
\end{tabular}

a Crude odds ratios.

b $95 \%$ confidence intervals that exclude one indicate statistical significance.

+ Analyses included all subjects.

++ Analyses included only ever-smokers.

NB Antisocial personality disorder was excluded since only three women met criteria. 
major depression was in the order of 2 , consistent with that observed in men, but the $95 \%$ confidence interval differed in showing borderline significance. For quit/cut down, only one diagnostic group among the women, ie, those with recurrent major depression, showed a statistically significant odds ratio; the magnitude of that negative association (OR $=0.1$ ) suggests a profound inability to stop smoking.

No association with either ever smoking or quit/cut down was observed for dysthymia, antisocial personality disorder, or the other anxiety disorders, ie, panic, simple phobia, agoraphobia, or obsessive-compulsive disorder. These data did not show an association between schizophrenia and ever-smoking; nonetheless it is noteworthy that none of the individuals with schizophrenia were able to quit or cut down.

\section{COMORBIDITY}

Results of further analyses that controlled for possible confounding due to comorbidity and demographic characteristics when the odds ratio for either ever-smoking or quit/cut down approached or reached statistical significance are shown in table 4 . For both genders, generalised anxiety disorder and alcohol abuse/dependence remained significantly associated with ever-smoking, indicating the independence of these relationships. Recurrent major depression continued to show a strong negative association with quit/cut down among women, as did generalised anxiety disorder among men. However, for both genders the odds ratios for the association between single major depression and eversmoking (borderline significant in the unadjusted analyses) were clearly nonsignificant when adjusted for comorbidity.

\section{Discussion}

The relationship between specific psychiatric disorders and cigarette smoking in a rep-

Table 4 Adjusted odds ratios showing the association between selected psychiatric disorders and cigarette smoking, (ever-smoking and quit/cut down), by gender

\begin{tabular}{llll}
\hline & Ever smoking & & Quit/cut down \\
& $O R \quad 95 \%$ CI & & OR $95 \%$ CI \\
\hline $\begin{array}{l}\text { Men: } \\
\text { Alcohol abuse/dependence }\end{array}$ & $2.3(1.6-3.4)$ & $0.7(0.5-1.1)$ \\
$\begin{array}{l}\text { Generalised anxiety } \\
\text { Major depression }\end{array}$ & $2.6(1.5-4.8)$ & $0.5(0.3-1.0)$ \\
$\quad \begin{array}{lll}\text { single type } \\
\text { recurrent type }\end{array}$ & $1.9(0.5-7.3)$ & $2.1(0.4-10.4)$ \\
$\begin{array}{l}\text { Women: } \\
\text { Alcohol abuse/dependence }\end{array}$ & $0.8(0.3-2.7)$ & $1.0(0.3-4.3)$ \\
$\begin{array}{l}\text { Generalised anxiety } \\
\text { Major depression } \\
\text { single type }\end{array}$ & $1.4(1.0-8.1)$ & $0.7(0.6-3.2)$ \\
$\quad$ recurrent type & $1.5(0.8-2.9)$ & $0.7(0.4-1.3)$ \\
\hline
\end{tabular}

1) ORs for alcohol dependence were adjusted for age, race, education, residence, and lifetime prevalence of major deeducation, residence, and lifetime prevale

pression and generalised anxiety disorder.
2 ) ORs for generalised anxiety were adjusted for age, race, 2) ORs for generalised anxiety were adjusted for age, race, education, residence, and lifetime prevale pression and alcohol abuse/dependence.

3) ORs for single and major depression were adjusted for age race, education, residence, and lifetime prevalence of generalised anxiety and alcohol abuse/dependence. resentative community sample was previously examined in St Louis, another ECA site. ${ }^{7}$ That study reported an association between major depression and both ever-smoking and smoking cessation but did not disaggregate by type of major depression. Alcohol abuse/ dependence, dysthymia, and agoraphobia were also associated with ever-smoking; however, when comorbidity with major depression was accounted for, only the effect of alcohol abuse/dependence remained significant. The present study was undertaken to replicate and refine those findings from St Louis and to examine the association between cigarette smoking and generalised anxiety disorder. (This latter condition had not been included in Wave 1 of the NIMH-ECA study, which provided the data for the St Louis report.)

To allow a direct comparison of findings regarding major depression between St Louis and Durham, odds ratios for ever-smoking and quitting by gender and type of major depression in each site are presented in table 5. In St Louis, a positive association between eversmoking and major depression, regardless of type, was observed for both genders; the odds ratios among the small number of male depressives, however, were nonsignificant. Quitting, on the other hand, was adversely related to all types of major depression in both genders; the odds ratios were significant for all but the single depression groups where the numbers for both genders were low. Such a broad effect of major depression on smoking behaviour was not evident in the Durham ECA data. For ever-smoking, a positive association, indicated by odds ratios of two or greater, was observed only for single major depression and only the odds ratio for women approached statistical significance. For quitting, nonsignificant odds ratios somewhat greater than one did not suggest a greater inability to quit among the men, and among the women, only those with recurrent major depression demonstrated a clear deficit for stopping or reducing smoking. In other words, these data from the Durham ECA do not

Table 5 Odds ratios for ever-smoking and quit/cut down in St Louis ECA, 1981-83* and Durham ECA $1981-83$

\begin{tabular}{|c|c|c|c|}
\hline $\begin{array}{l}\text { Types of major } \\
\text { depression }\end{array}$ & $\begin{array}{c}\text { Total } \\
(n)\end{array}$ & $\begin{array}{c}\text { Ever-smoking } \\
\text { OR }^{a}(95 \% C I)^{b}\end{array}$ & $\begin{array}{l}\text { Quit/cut down } \\
O R^{a}(95 \% C I)^{b}\end{array}$ \\
\hline \multicolumn{4}{|c|}{ St Louis ECA-Men } \\
\hline combined & 50 & $1.9(0.9-3.8)$ & $0.3(0.1-0.9)$ \\
\hline recurrent & 43 & $1.5(0.7-3.1)$ & $0.3(0.1-0.98)$ \\
\hline single & 7 & $6.9(0.4-122.4)$ & $0.3(0.03-2.3)$ \\
\hline \multicolumn{4}{|c|}{ St Louis ECA - Women } \\
\hline combined & 145 & $2.7(1.8-3.8)$ & $0.6(0.3-1.0)$ \\
\hline recurrent & 116 & $2.6(1.7-4.0)$ & $0.4(0.3-0.9)$ \\
\hline single & 29 & $2.7(1.2-6.2)$ & $0.6(0.2-2.2)$ \\
\hline \multicolumn{4}{|c|}{ Durham ECA - Men } \\
\hline combined & 24 & $1.4(0.6-3.5)$ & $1.3(0.5-3.4)$ \\
\hline recurrent & 14 & $1.1(0.4-3.2)$ & $1.3(0.4-4.3)$ \\
\hline single & 10 & $2.5(0.5-13.3)$ & $1.4(0.3-5.9)$ \\
\hline \multicolumn{4}{|c|}{ Durham ECA - Women } \\
\hline combined & 78 & $1.5(0.98-2.3)$ & $0.7(0.3-1.4)$ \\
\hline recurrent & 47 & $1.1(0.6-2.1)$ & $0.1(0.01-0.95)$ \\
\hline single & 25 & $2.0(1.0-4.1)$ & $0.9(0.3-2.6)$ \\
\hline
\end{tabular}

* Data courtesy of Dr Linda Cottler, University of Missouri.

Crude odds ratios.

$95 \%$ confidence intervals that exclude one indicate statistical significance. 
entirely replicate the observations regarding major depression in St Louis. These present findings also differ from those of Breslau et $a l^{9}$ who reported a significant association between nicotine dependence and major depression, and Kendler et $a l^{12}$ who suggested a genetic diathesis between major depression and cigarette smoking.

The confluence of several factors may account for the negative observations in Durham. First, although the uniform sampling design employed across centres in the NIMH-ECA resulted in comparable demographic distributions among the sites, there were differences in rates of specific disorders. Most pertinently for the smoking/major depression relationship, lifetime prevalence rates of major depression and other affective disorders were about two times higher in St Louis than in Durham, ${ }^{17}$ resulting in a lack of power to detect statistical significance in Durham. Indeed, to observe a significant ( $a=0.05 \%$, $1-b=80 \%$ ) odds ratio of two or greater for the major depression-cigarette smoking relationship as seen in St Louis ${ }^{7}$ and the Breslau et $a l^{9}$ study, the sample sizes required are 165 for men and 132 for women, ${ }^{23}$ certainly beyond the samples available in the present data set $(24$ men and 78 women). Moreover, it is possible that, because of the prominence of tobacco farming and cigarette manufacturing in the state, citizens of North Carolina are more tolerant of cigarette smoking, diminishing the value of cigarette smoking as an emolient for emotional distress.

The observed association between recurrent major depression and quitting among women in the Durham ECA is noteworthy. In spite of the relatively small number $(n=47)$ of women with recurrent major depression, their odds ratio for quitting was statistically significant. Such a dominant effect of recurrent major depression among female smokers has been seen elsewhere. Similarly, in a clinical trial of clonidine for smoking cessation, recurrent major depression was the strongest baseline predictor of inability to quit among female participants who were assigned to the placebo condition. ${ }^{24}$ The validity and generalisability of these congruent findings regarding a stronger influence of recurrent major depression on quitting require further study. They would have implications on the efficacy of smoking cessation interventions tailored to address a history of vulnerability to depression.

Our findings on generalised anxiety disorder add to the limited knowledge about anxiety disorders and cigarette smoking. The observation that generalized anxiety is associated with an increased likelihood of being an eversmoker for both genders is consistent with earlier work by Breslau et $a l^{9}$ and Hughes et $a l^{4}$. The present data also demonstrated an adverse relationship between generalised anxiety and quitting. Albeit significant in men only, this observation, to our knowledge, is without precedent. While such a finding would seem to be intuitive, we did not observe it in the Columbia University Smoking Clinic where only $3 \%$ of participants met criteria for generalised anxiety disorder (in contrast, 35\% of all participants reported past major depression) ${ }^{24}$ Perhaps the link between smoking and generalised anxiety is so strong that smokers with this disorder are unlikely to attempt to stop smoking or, discouraged by failed past attempts, to seek aid from a smoking-cessation clinic.

In contrast with findings about major depression, data regarding alcoholism from the Durham ECA do correspond with those from the St Louis study in pointing to a significant association between alcoholism and eversmoking. The present data extend that observation by showing that the relationship occurs for both genders independently of major depression and generalised anxiety. In addition to these ECA data, there have been similar reports of an association between eversmoking status and alcoholism. ${ }^{9,25}$ The evidence about quitting smoking among alcoholics, however, is sparse and the present findings augment that literature. Both the crude and the adjusted odds ratios for quit/cut down among women with alcoholism reflect fewer quitters but, possible due to the small numbers, neither odds ratio was statistically significant. Among male alcoholics, the crude odds ratio also indicated a reduced ability to quit that approached statistical significance; however, the odds ratio after adjustment for comorbidity with major depression and generalised anxiety was no longer significant. This suggests that, by itself, alcoholism was not associated with the ability to quit or cut down smoking. These results are consistent with recent findings from a smoking cessation trial indicating that male smokers with a history of alcoholism but not history of major depression were equally likely to stop smoking as nonalcoholic males; however, alcoholics who also had a history of major depression had a significantly poorer outcome. ${ }^{26}$ Such correspondence between results occurred in spite of differences between study samples. The alcoholic subjects in the clinical trial had all been abstinent from alcohol for at least six months and were seeking treatment for their nicotine addiction, whereas subjects in the ECA study included active as well as former alcoholics who may or may not have ever sought smoking-cessation treatment.

Because it disagrees with previous knowledge, the observed lack of association between smoking behaviour and dysthymia, antisocialpersonality disorder, and schizophrenia, deserves comment. Dysthymia is an affective disorder characterised by chronic depressive mood, a condition that has been shown to relate significantly with higher smoking and lower cessation rates ${ }^{26}$ antisocial personality disorder has been closely linked with alcoholism $;^{28}$ and several studies have reported higher rates of smoking among individuals with schizophrenia. ${ }^{14,15}$ A plausible reason for these negative relationships is that the very small numbers of these disorders in this data set (see tables 2 and 3 ) did not provide an adequate representation of smoking behaviour within those diagnostic groups. 
The results of this study add to a growing literature that has identified relationships between cigarette smoking and psychiatric syndromes. The nature and the basis of these relationships, however, remain to be clarified. It is plausible that individuals vulnerable to certain psychiatric disorders are more likely to begin and continue to use nicotine, the main pharmacological substance in tobacco smoke, as a form of self-medication. On the other hand, given that the onset of cigarette smoking typically occurs during adolescence, it is also plausible that chronic, heavy exposure of the central nervous system to various pharmacological ingredients in tobacco has a role in promoting, if not initiating, psychiatric morbidity. Studies that would test these hypotheses are indicated.

A further possibility, the existence of an underlying diathesis, has recently received support from two investigations. Studying 955 young adults who were first seen in 1989 and then again in 1990, Breslau et al found that: a) smokers with a history of major depression at Time 1 were at increased risk for progression to nicotine dependence or its increased severity at Time 2 , and $b$ ) smokers with a history of nicotine dependence at Time 1 were at increased risk for first incidence major depression. ${ }^{11}$ Thus, either condition, ie, nicotine dependence or major depression, predicted the other, a situation that suggests a shared vulnerability. While Breslau et al's finding did not clarify whether that shared factor is environmental or genetic, analysis of data from 1566 female twins by Kendler et al, ${ }^{12}$ showed that shared genes, rather than a common environment, more convincingly explained the relationship between major depression and cigarette smoking.

Associations between specific psychiatric disorders and cigarette smoking provide clues to the management of anti-smoking interventions. Success rates of cessation programmes could be improved by incorporating psychiatric screening procedures and tailoring the course of treatment if a psychiatric history is detected. The demonstration by Hall et $a l^{8}$ that an affect regulation protocol increased the cessation rate among smokers with a past history of major depression, but not in smokers without such a history, supports this proposition.

Cigarette smoking has traditionally been an issue for nonpsychiatric medicine. Increased awareness of its linkage with the most common psychiatric disorders, ie, alcoholism, major depression, generalised anxiety, and schizophrenia, may also serve psychiatry by increasing knowledge regarding the neurophysiology of these "smoking-related" psychiatric disorders and improving their clinical management.

This study was supported by NIDA Grant DA04732, and NIMH grants MH35386, MH43756, MH40159.
1 Waal-Manning HK, Jamel FA. Smoking habit and psychometric scores: a community study. $N Z M e d \mathcal{F} 1978 ; 88$ : 188-91.

2 Pomerleau O, Adkins D, Pertschuk M. Predictors of outcome and recidivism in smoking cessation treatment Addict Behav 1978; 3: 65-70.

3 Shiffmann S. Relapse following smoking cessation: situational analysis. f Consult Clin Psychol 1982; 50: $71-86$.

4 Hughes JR, Hatsukami DK, Mitchell JE, et al. Prevalence of smoking among psychiatric outpatients. Am f Psychiatry 1986; 143:993-7.

5 Carney RM, Rich MW, TeVelde A, et al. The relationship between heart rate, heart rate variability and depression in patients with coronary artery disease. F Psychosom Res $1988 ; 31: 159-64$

6 Glassman AH, Stetner F, Walsh BT, et al. Heavy smokers, smoking cessation, and clonidine: results of a doubleblind, randomized trial. $\mathcal{f} A M A 1988 ; 259: 2863-6$

7 Glassman AH, Helzer JE, Covey LS, et al. Smoking, smoking cessation, and major depression. $\mathcal{F} A M A 1990$ 264: 1546-9.

8 Hall SM, Munoz R, Reus V. Depression and smoking treatment: A clinical trial of an affect regulation treatment. In: Harris, LS, ed. Proceedings of the 53rd Annual Scientific Committee on Drug Dependence, Inc. NIDA Research Monograph Series, No 119.1992. Rockville, Maryland: US Department of Health and Human Services, Public Health Service, 1992 (DHHS Publication No (ADM) 92-1882.)

9 Breslau N, Kilbey M, Andreski P. Nicotine dependence, major depression and anxiety in young adults. Arch Gen Psychiatry 1991; 48: 1069-74.

10 Breslau N, Kilbey M, Andreski P. Nicotine withdrawal symptoms and psychiatric disorders: findings from an epidemiologic study of young adults. Am F Psychiatry 1992; 149: 464-9.

11 Breslau N, Kilbey M, Andreski P. Nicotine dependence and major depression: new evidence from a prospective investigation. Arch Gen Psychiatry 1993; 50: 31-5.

12 Kendler KS, Neale MC, MacLean CJ, et al. Smoking and major depression: a causal analysis. Arch Gen Psychiatry major depression

13 Pohl RB, Yeragani VK, Balon R, et al. Smoking in panic disorder patients. Proceedings of the 145th Annual Meeting of the American Psychiatric Association, 2-17 May 1992, Washington, DC.

14 Calabresi M, Casu G, Luche RD. The prevalence of tobacco smoking in psychiatric patients. The influence of the factor 'institutionalization'. Min Psychiatr 1991; 32: 89-92.

15 Masterson E, O'Shea B. Smoking and malignancy in schizophrenia. Br f Psychiatry 1992; 145: 429-32.

16 US Department of Health and Human Services. Reducing the health consequences of smoking : 25 years of progress. $A$ report of the Surgeon General, 1989. Atlanta, Georgia: report of the Surgeon General, 1989. Atlanta, Georgia: Centers for Disease Control, Office on Smoking and

17 Robins LN, Regier DA (eds). Psychiatric disorders in America. New York: The Free Press, 1991.

18 Glassman AH, Covey LS, Dalack GW, et al. Smoking cessation, clonidine, and vulnerability to nicotine among dependent smokers. Clin Pharm Therapeut 1993; 54: 670-9.

19 Leaf PJ, Myers JK, McEvoy LT. Procedures used in the epidemiologic catchment area study. In: Robins $\mathrm{LN}$, Regier DA, eds. Psychiatric disorders in America. 1991, New York: The Free Press, 1991, pp. 180-203.

20 Kish L. Sampling. New York: Wiley \& Sons, 1985.

21 Robins LN, Helzer JE, Croughan J, Ratcliff KS. National Institute of Mental Health Diagnostic Interview Schedunstitute of Mental Health Diagnostic Interview Schedule: its history, characteristics
Psychiatry $1981 ; 38: 381-90$.

22 American Psychiatric Association. Diagnostic and statistical manual of mental disorders (third edn). Washington DC: APA, 1980

23 Schlesselman JJ. Case-control studies: design, conduct, analysis. New York: Oxford University Press, 1981.

24 Covey LS, Glassman AH, Stetner F. Gender differences in the effects of major depression and level of nicotine addition on smoking cessation. Paper read at the 6 th Annual Meeting of the ASAM on nicotine dependence, Atlanta, Georgia, 11-15 November 1993.

25 DiFranza JK, Guerrera MP. Alcoholism and smoking. $\mathcal{f}$ Stud Alcohol 1990; 51 : 130-5.

26 Covey LS, Glassman AH, Stetner F, Becker J. Effect of history of alcoholism or major depression on smoking history of alcoholism or major depression on

27 Anda RF, Williamson DF, Escobedo LG, Mast EE, Giovino GA, Remington PL. Depression and the dynamics of smoking. F $A M A$ 1990; 264: 1541-5.

28 Ross HE, Glaser B, Germanson T. The prevalence of psychiatric disorders in patients with alcohol and other drug problems. Arch Gen Psychiatry 1988; 45: 1023-31. 